\title{
Experimental and Theoretical Investigations of Mouldability for Feedstocks Used in Powder Injection Moulding
}

\author{
Çetin Karataş, Adnan Sözen, Erol Arcaklioglu, and Sami Erguney
}

Received 11 September 2006; Accepted 8 March 2007

Recommended by Agostino Bruzzone

\begin{abstract}
Experimental and theoretical analyses of mouldability for feedstocks used in powder injection moulding are performed. This study covers two main analyses. (i) The experimental analysis: the barrel temperature, injection pressure, and flow rate are factors for powder injection moulding (PIM). Powder-binder mixture used as feedstock in PIM requires a little more attention and sensitivity. Obtaining the balance among pressure, temperature, and especially flow rate is the most important aspect of undesirable conclusions such as powder-binder separation, sink marks, and cracks in moulded party structure. In this study, available feedstocks used in PIM were injected in three different cavities which consist of zigzag form, constant cross-section, and stair form (in five different thicknesses) and their mouldability is measured. Because of the difference between material and binder, measured lengths were different. These were measured as $533 \mathrm{~mm}, 268 \mathrm{~mm}, 211 \mathrm{~mm}$, and $150 \mathrm{~mm}$ in advanced materials trade marks $\mathrm{Fe}-2 \mathrm{Ni}, \mathrm{BASF}$ firm Catamould A0-F, FN02, and 316L stainless steel, respectively. (ii) The theoretical analysis: the use of artificial neural network (ANN) has been proposed to determine the mouldability for feedstocks used in powder injection moulding using results of experimental analysis. The back-propagation learning algorithm with two different variants and logistic sigmoid transfer function were used in the network. In order to train the neural network, limited experimental measurements were used as training and test data. The best fitting training data set was obtained with three and four neurons in the hidden layer, which made it possible to predict yield length with accuracy at least as good as that of the experimental error, over the whole experimental range. After training, it was found that the $R^{2}$ values are $0.999463,0.999445,0.999574$, and 0.999593 for $\mathrm{Fe}-2 \mathrm{Ni}$, BASF firm Catamould A0-F, FN02, and 316L stainless steel, respectively. Similarly, these values for testing data are $0.999129,0.999666,0.998612$, and 0.997512, respectively. As seen from the results of mathematical modeling, the calculated yield lengths are obviously within acceptable uncertainties.
\end{abstract}

Copyright (c) 2007 Çetin Karataş et al. This is an open access article distributed under the Creative Commons Attribution License, which permits unrestricted use, distribution, and reproduction in any medium, provided the original work is properly cited.

\section{INTRODUCTION}

Powder injection moulding (PIM) is a powder production method that is used to produce parts which are small, complex-shaped, high-dimension precise, with smooth surface, difficult to machine, with a low cost.

Most stages of the PIM are similar to the stages of polymer injection moulding. Equipments and mould design of PIM are based on the polymer injection moulding method. In PIM processing, the powder flow and thermal behavior efficiency of materials look like thermoplastics; however, some extra attention should also be paid to the adequate mould filling. The most efficient mixture temperature requires a temperature that gives a viscosity lower than 100 Pa.s and varies with mixtures. For continuous plastic transformation, powder-binder mixture in injection cylinder should be homogeneous, and heat transfer into the filling polymer should be fast. Reverse fast cooling behavior may lead to some prob- lems. As a result, to minimize the stress and shrinkage, mould should be heated during the filling $[1,2]$.

The progress of neurobiology has allowed researchers to build mathematical models of neurons to simulate neural behavior. Artificial neural network (ANN) approach is a wellknown type of evolutionary computation methods in the last decades. Also ANN technique has been adapted for a large number of applications in different scientific areas [3-11]. In the field of process engineering, ANNs are a good alternative to conventional empirical modeling based on polynomial and linear regressions.

The aim of the present study is to propose a new approach based on ANNs to determine the mouldability for feedstocks used in powder injection moulding. This study consists of two cases.

(i) The experimental analysis: in this case, to examine the flow and filling, the most optimum mouldability parameters such as injection temperature, injection pressure, injection 


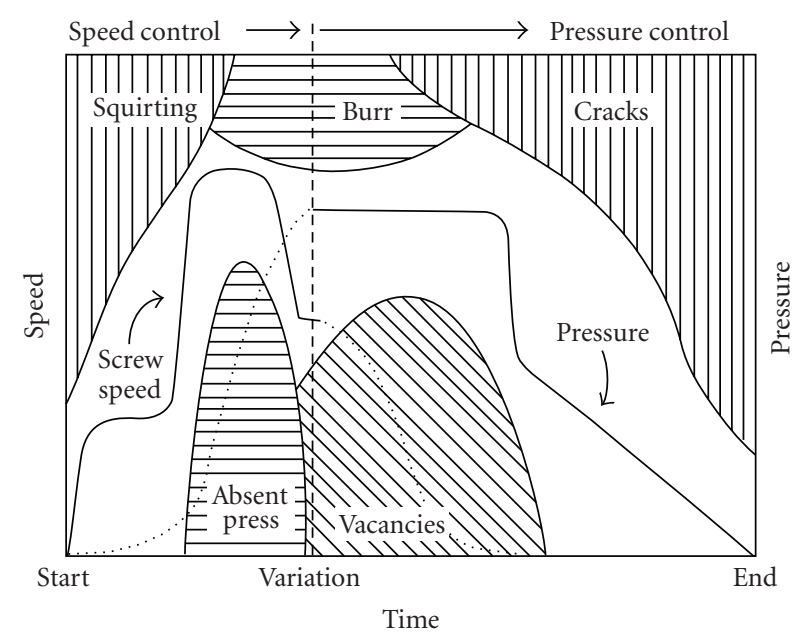

FIgURE 1: Schematic diagram that shows the formation condition of rate and press control according to the time for mould defects $[2]$.

flow, and mould temperature were investigated by feeding the feedstocks, manufactured for PIM, into the moulding manufactured for this purpose.

(ii) The theoretical analysis: the use of ANN has been proposed to determine the yield length in moulding as analytic formula at different barrel temperature, injection pressure, and flow rate using results of experimental analysis. The back-propagation learning algorithm with two different variants and logistic sigmoid transfer functions were used in the network. In order to train the neural network, limited experimental measurements were used as training and test data. The importance of the ANN approach, apart from reducing the time required, is that it is possible to make mould applications more viable and thus more attractive to potential users such as design engineers.

\section{EXPERIMENTAL ANALYSIS}

\subsection{Mouldability}

Mouldability is defined as gauge of rate and ease of shaping of feedstock for a given characteristic. With a simple approach, related pressure, rate, and time for moulding are given in Figure 1. Figure 1 shows the behavior of the whole moulding processing. Here, until the mould vacancy fills, screw control supervises the process. This is shown in the left side of Figure 1. Pressure control for vacancy is used during ironing and cooling. That is also shown in the right side of Figure 1. When mould vacancy is filled and pressure is applied, transformation of feedstock from molten to solid occurs. This transformation is related to errors originating from screw rate of movements in mould deadheading pays. As a result, there is restrictive region between process parameters and component of feedstock and the geometry of mould vacancy. This restrictive region is for the defective parts $[1,2,12]$.

Incomplete filling occurs under low pressure and temperature. At high temperature and pressure, the sample will

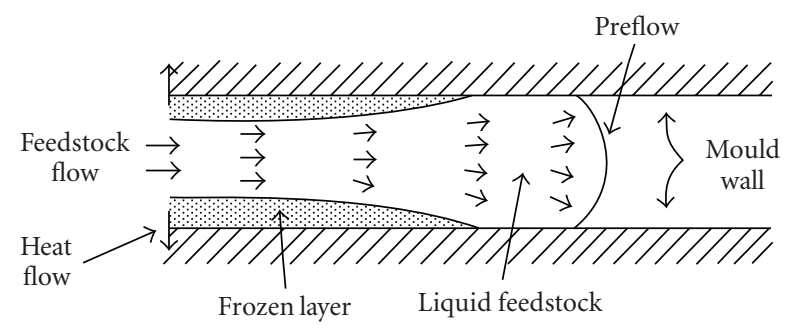

Figure 2: Molten feedstock flow along the mould canal.

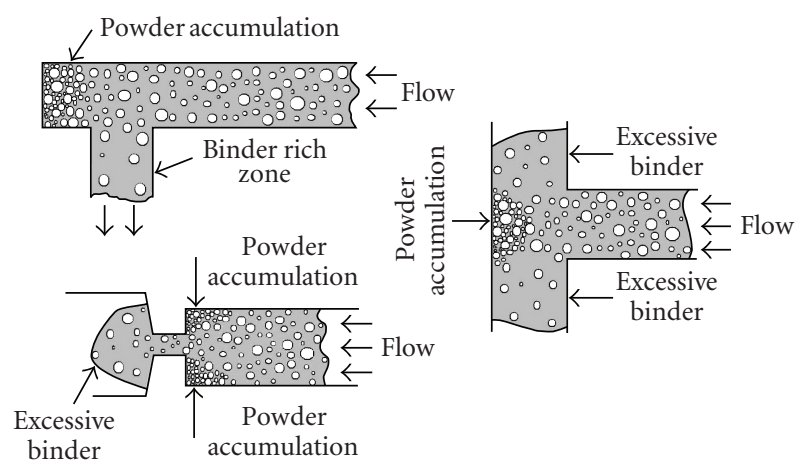

FIGURE 3: Separation of powder-binder during the direction change $[2,13]$.

stick to the mould wall or it will give burred surface along the separation line. Elevated pressures and temperatures give good moulding results. The aim of the studies of mouldability is to generate good mouldability situation by controlling the conditions $[2,12-14]$.

A frozen layer is formed along the mould wall due to cold mould. Heat flow is to wall from frozen layer. Middle canal starts to fill while getting closer vacancy filling later. For this reason completely filling the long canal is a sign of success $[1,2,14-16]$; see Figure 2.

When the PIM products are compared with polymers, they have higher thermal activity that leads to fast solidification. For this reason, very high injection rate is used. However, high rates cause problems in case sudden direction changes. The most important two of these problems are powder accumulation and separation of binder. Separation of powder-binder due to sudden directional change leads to defects in sample during the subsequent process of debinding and sintering $[2,13]$. Debinding is bidirectional during the directional change; in the new direction an accumulation of stones occurs and in the direction of melt a binder rich zone is formed. Such zones lead to inappropriate shrinkage during the sintering [12-16]; Figure 3.

A zigzag mould design was obtained for PIM mouldability test (Figure 4). Side arms of these moulds force the flow to change the direction. If powder and binder separate, powder rich zones are formed at the end of each arm. In advance to filling of powder rich end zone, binder rich region continues to flow through the side arm. The case of separation of powder and binder is not desired, because the separation of 
TABLE 1: Feedstocks and their chemical contents.

\begin{tabular}{l|cc}
\hline Feedstock & Picnometer density $\left(\mathrm{g} / \mathrm{cm}^{3}\right)$ & Chemical content \\
\hline Catamould FN02 & 4.53 & Hardenable carbon steel with 2\% nickel addition \\
Catamould 316L & 5.04 & nonmagnetic X2 CrNiMo 17 13 2 DIN 1.4404 AISI/SAE 316L UNS S31603 \\
Catamould A0-F & 2.81 & Aluminum oxide 99,8\% \\
Fe-2Ni-Res-9903 & 4.83 & $\% 2 \mathrm{Ni}, \% 0.76 \mathrm{C}, \% 0.71 \mathrm{~N}, \% 0.32 \mathrm{Si}$ \\
\hline
\end{tabular}

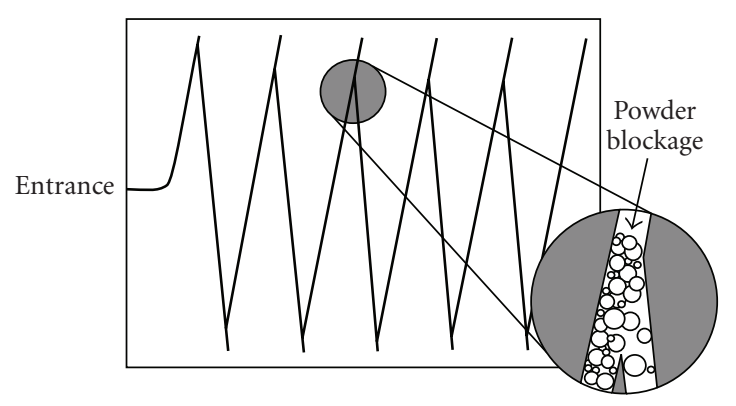

FIgURE 4: Zigzag test mould used for PIM feed stock experiments $[2,13]$.

powder and binder is one of the most important reasons for the differences in sintering and distortion. For this reason, zigzag mould test is very important to succeed in separating the powder binder as well as the mouldability [13].

Capillary rheometer tests (flow criteria) are useful to characterize the mouldability because of the measurability of viscosity as a function of temperature and slide ratio. However, using the rheologic data for practical estimation of mouldability is difficult. At higher temperatures and higher solid feed, ahead the low viscosity rheometer puts a base and proves the evaluation of behavior of relative feedstock [2].

\subsection{Feedstock}

In this study, Catamould FN02, Catamould 316L made by BASF and Fe-2Ni-Res-9903 made by advanced metalworking moulds were used (Table 1).

ARBURG Allrounder 220S type plastic injection machine, TOOL-TEMP TT-157 E type mould conditioner to keep the temperature constant through the process, and JEOL JSM 6360V electron microscope were used.

\subsection{Injection mould}

In this study, yield length of feedstock is examined by pressing in a mould having a zigzag canal with $2.5 \mathrm{~mm}$ radius and $800 \mathrm{~mm}$ length. This mould has also a staircase-shaped vacancy with the dimension of 0.5-1-2-5-10 mm, and a vacancy with the dimension of $90 \times 12.7 \times 7 \mathrm{~mm}$ (Figure 5.)

\subsection{Experimental procedure}

In this study, the effects of four different feedstocks, mould conditions, and injection parameters on mouldability and yield length were investigated. In a mould which is attached
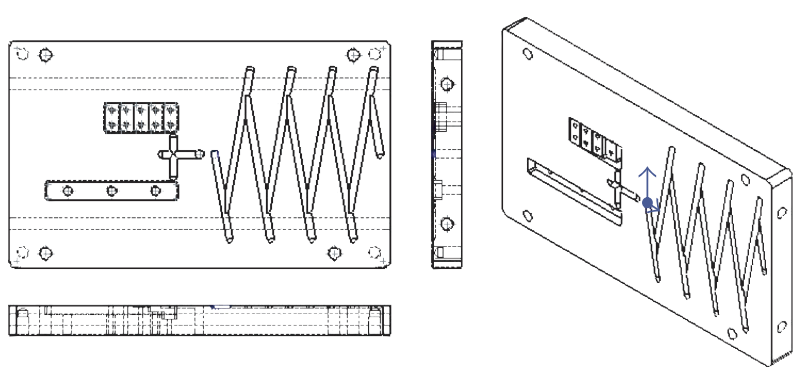

FIGURE 5: Zigzag-shaped yield length measurement mould.

to injection machine and has a zigzag canal, the effects of injection temperature and pressure and injection flow on present feedstocks samples, were pressed and the length in the zigzag canal was measured.

During the experiment, one sample was obtained after each parameter change. Pressure, cylinder temperature, flow, and mould temperature used injection moulding were tabulated in Table 2.

\section{THEORETICAL ANALYSIS}

\subsection{Artificial neural networks}

ANNs have been widely used for many areas, such as control, data compression, forecasting, optimization, pattern recognition, classification, speech, vision, and so forth. The use of the ANNs for modeling and prediction purposes is increasingly becoming popular in the last decades [1-11].

The system has three layers which are an input layer, a hidden layer, and an output layer. The input layer consists of all the input factors, information from the input layer is then processed in the course of one hidden layer, followed by output vector which is computed in the final (output) layer. Generally, hidden and output layers have an activation function. A sigmoid function as an activation function is a widely used nonlinear activation function [8] whose output lies between 0 and 1.

An important stage of a neural network is the training step, in which an input is introduced to the network together with the desired output, the weights and bias values are initially chosen randomly and the weights are adjusted so that the network attempts to produce the desired output. The weights, after training, contain meaningful information, whereas before training, they are random and have no meaning. When a satisfactory level of performance is reached, the 
TABLE 2: Injection parameters.

\begin{tabular}{lccc}
\hline Injection pressure (bar) & Cylinder temperature $\left({ }^{\circ} \mathrm{C}\right)$ & Injection moulding $\left(\mathrm{cm}^{3} / \mathrm{s}\right)$ & Mould temperature $\left({ }^{\circ} \mathrm{C}\right)$ \\
\hline 600 & 170 & 5 & 32 \\
800 & 180 & 10 & 75 \\
1000 & 190 & 15 & 140 \\
1200 & 200 & 20 & - \\
1400 & 210 & 25 & - \\
1600 & 220 & 30 & - \\
- & 230 & 35 & - \\
\hline
\end{tabular}

training stops, and the network uses the weights to make decisions.

Many alternate training processes are available such as back-propagation, which has different variants. The goal of any training algorithm is to minimize the global error such as mean \% error, root-mean-squared (RMS), and $R^{2}$. An important characteristic of this function is differentiable throughout its domain. The error for hidden layers is determined by propagating back the error determined for the output layer. follows:

Error during the learning is called RMS and defined as

$$
\mathrm{RMS}=\left(\left(\frac{1}{p}\right) \sum_{j}\left|t_{j}-o_{j}\right|^{2}\right)^{1 / 2} .
$$

In addition, absolute fraction of variance $\left(R^{2}\right)$ and mean absolute percentage error (MAPE) are defined as follows, respectively:

$$
\begin{gathered}
R^{2}=1-\left(\frac{\sum_{j}\left(t_{j}-o_{j}\right)^{2}}{\sum_{j}\left(o_{j}\right)^{2}}\right), \\
\text { MAPE }=\frac{o-t}{o} * 100,
\end{gathered}
$$

where $t$ is target value, $o$ is output value, and $p$ is pattern value [9]. Input and output layers are normalized in the $(-1,1)$ or $(0,1)$ range.

ANNs have been used in a broad range of applications including pattern classification, function approximation, optimization, prediction, and automatic control [9]. The back-propagation learning algorithm has been used in feedforward single hidden layers. Variants of the algorithm used in the study are scaled conjugate gradient (SCG) and Levenberg-Marquardt (LM). Inputs and outputs are normalized in the $(-1,1)$ range. Neurons in input layer have no transfer function. Logistic sigmoid (logsig) transfer function has been used. The transfer function used is

$$
f(z)=\frac{1}{1+e^{-z}},
$$

where $z$ is the weighted sum of the input.

\subsection{Application}

Computer program has been performed under MATLAB in order to use different algorithms and neurons in the ANN.

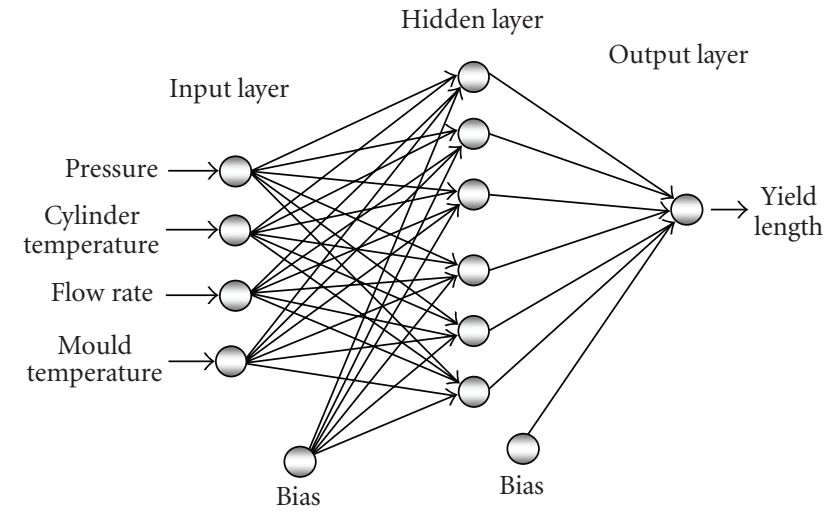

FiguRE 6: ANN architecture.

Here ANN is used for modeling yield length in mould. Inputs for the network are pressure, flow rate, mould temperature, and cylinder temperature; output is yield length. Figure 6 shows the single hidden-layer ANN architecture used in our application.

The new formula of the output as the best algorithm SCG with 4 neurons is given (4) for BASF firm Catamould A0F. This equation can be used to estimate yield length in the mould where known process parameters are

$$
\mathbf{Y L}_{\mathrm{A} 0-\mathrm{F}}=\frac{\mathbf{1}}{\mathbf{1}+\mathbf{e}^{-\left(-0.6309 F_{1}-6.2172 F_{2}+0.9975 F_{3}+6.3704 F_{4}-2.959\right)}},
$$

where $F_{i}$ can be calculated according to (5). The formula for the prediction of yield length in mould (4) is dependent on moulding parameters as seen in (6):

$$
F_{i}=\frac{1}{1+e^{-E_{i}}},
$$

where $E_{i}$ is given (6), which is moulding parameters:

$$
E_{i}=C_{1 i} * \mathrm{CT}+C_{2 i} * \mathrm{P}+C_{3 i} * \mathrm{FR}+C_{4 i} * \mathrm{MT}+C_{5 i} .
$$

The constants $\left(C_{i j}\right)$ in (6) are given in Table 3.

Similarly, the new formulas of the output as the best algorithm SCG with 4 neurons, LM with 3 neurons, and LM with 4 neurons are given (7) for $\mathrm{FN} 02, \mathrm{Fe}-2 \mathrm{Ni}$, and $316 \mathrm{~L}$ stainless steel, respectively. These equations can be used to estimate 
TABLE 3: Constants in (6) obtained by SCG algorithm with 4 neurons.

\begin{tabular}{l|rrrrr}
\hline \multirow{2}{*}{$i$} & \multicolumn{5}{|c}{ Constants for (6) } \\
\cline { 2 - 6 } & \multicolumn{1}{|c}{$C_{1 i}$} & \multicolumn{1}{c}{$C_{2 i}$} & \multicolumn{1}{c}{$C_{3 i}$} & \multicolumn{1}{c}{$C_{4 i}$} & \multicolumn{1}{c}{$C_{5 i}$} \\
\hline 1 & 2.4914 & 4.8335 & -2.1974 & 7.1626 & -8.0053 \\
2 & -3.2333 & -2.3844 & -0.5510 & -0.6651 & 4.6082 \\
3 & -5.3732 & -7.2194 & -0.3189 & 0.1571 & 8.5420 \\
4 & -0.4859 & 0.6690 & 19.1268 & 5.9300 & -0.6356 \\
\hline
\end{tabular}

TABLE 4: The weights between input layer and hidden layer for FN02.

\begin{tabular}{r|rrrrr}
\hline \multirow{2}{*}{$i$} & \multicolumn{5}{|c}{$E_{i}=C_{1 i} * \mathrm{CT}+C_{2 i} * P+C_{3 i} * \mathrm{FR}+C_{4 i} * \mathrm{MT}+C_{5 i}$} \\
\cline { 2 - 6 } & \multicolumn{1}{|c}{$C_{1 i}$} & \multicolumn{1}{c}{$C_{2 i}$} & \multicolumn{1}{c}{$C_{3 i}$} & \multicolumn{1}{c}{$C_{4 i}$} & \multicolumn{1}{c}{$C_{5 i}$} \\
\hline 1 & -30.0670 & -2.0510 & -12.0376 & -9.0621 & 30.1897 \\
2 & 7.3823 & 7.2679 & -11.7743 & 1.1232 & -5.3141 \\
3 & -7.6696 & -3.2846 & -10.7568 & 0.4640 & 4.4136 \\
4 & 9.4738 & -9.8601 & 5.4982 & -4.0309 & 6.4619 \\
\hline
\end{tabular}

TABLE 5: The weights between input layer and hidden layer for $\mathrm{Fe}-2 \mathrm{Ni}$.

\begin{tabular}{r|rrrrr}
\hline \multirow{2}{*}{$i$} & \multicolumn{5}{|c}{$E_{i}=C_{1 i} * \mathrm{CT}+C_{2 i} * P+C_{3 i} * \mathrm{FR}+C_{4 i} * \mathrm{MT}+C_{5 i}$} \\
\cline { 2 - 6 } & \multicolumn{1}{|c}{$C_{1 i}$} & \multicolumn{1}{c}{$C_{2 i}$} & \multicolumn{1}{c}{$C_{3 i}$} & \multicolumn{1}{c}{$C_{4 i}$} & \multicolumn{1}{c}{$C_{5 i}$} \\
\hline 1 & 14.0376 & 11.2986 & 21.1265 & 0.4865 & -15.4581 \\
2 & -2.6309 & -8.9653 & -32.7151 & 7.6853 & 15.7506 \\
3 & 8.0538 & -6.2073 & -39.9853 & -1.8748 & 13.4369 \\
\hline
\end{tabular}

TABLE 6: The weights between input layer and hidden layer for 316L.

\begin{tabular}{r|rrrrr}
\hline \multirow{2}{*}{$i$} & \multicolumn{5}{|c}{$E_{i}=C_{1 i} * \mathrm{CT}+C_{2 i} * P+C_{3 i} * \mathrm{FR}+C_{4 i} * \mathrm{MT}+C_{5 i}$} \\
\cline { 2 - 6 } & \multicolumn{1}{|c}{$C_{1 i}$} & \multicolumn{1}{c}{$C_{2 i}$} & \multicolumn{1}{c}{$C_{3 i}$} & \multicolumn{1}{c}{$C_{4 i}$} & \multicolumn{1}{c}{$C_{5 i}$} \\
\hline 1 & -18.2060 & 0.0458 & -3.4031 & 8.9875 & 6.6427 \\
2 & 0.5202 & -2.2229 & -3.0021 & 6.3676 & 3.8423 \\
3 & 8.9857 & 4.5141 & 5.6770 & 13.6497 & -11.7285 \\
4 & 12.7485 & -0.7047 & 3.1882 & -3.2476 & -3.5585 \\
\hline
\end{tabular}

yield length in the mould where known process parameters are

$$
\begin{aligned}
\mathrm{YL}_{\mathrm{FN} 02} & =\frac{\mathbf{1}}{\mathbf{1}+\mathbf{e}^{-\left(-8.3518 F_{1}+0.7482 F_{2}-8.7813 F_{3}+4.523 F_{4}+2.6568\right)},} \\
\mathrm{YL}_{\mathrm{Fe}-2 \mathrm{Ni}} & =\frac{\mathbf{1}}{\mathbf{1}+\mathbf{e}^{-\left(1.1453 F_{1}-2.81182 F_{2}+2.7358 F_{3}-1.0451\right)}}, \\
\mathrm{YL}_{316 \mathrm{~L}} & =\frac{\mathbf{1}}{\mathbf{1}+\mathbf{e}^{-\left(-3.341 F_{1}+5.3258 F_{2}+1.2802 F_{3}-8.9476 F_{4}+1.9964\right)}},
\end{aligned}
$$

where $F_{i}$ can be calculated according to (5) and similarly, $E_{i}$ and the constants $\left(C_{i j}\right)$ are given in Tables $4-6$, which are moulding parameters for $\mathrm{FN} 02, \mathrm{Fe}-2 \mathrm{Ni}$, and $316 \mathrm{~L}$ stainless steel, respectively.

The input and output values in network need normalization" according to

$$
V_{N}=0.8 \times\left[\frac{V_{R}-V_{\min }}{V_{\max }-V_{\min }}\right]+0.1 .
$$

TABLE 7: Values for normalization.

\begin{tabular}{l|rr}
\hline & $V_{\min }$ & $V_{\max }$ \\
\hline Pressure (P) (bar) & 400 & 1800 \\
Cylinder temperature $(\mathrm{CT})\left({ }^{\circ} \mathrm{C}\right)$ & 100 & 300 \\
Flow rate (FR) $\left(\mathrm{cm}^{3} / \mathrm{sn}\right)$ & 3 & 50 \\
Mould temperature $(\mathrm{MT})\left({ }^{\circ} \mathrm{C}\right)$ & 20 & 170 \\
Yield length $(\mathrm{mm})(\mathrm{YL})$ & 10 & 600 \\
\hline
\end{tabular}

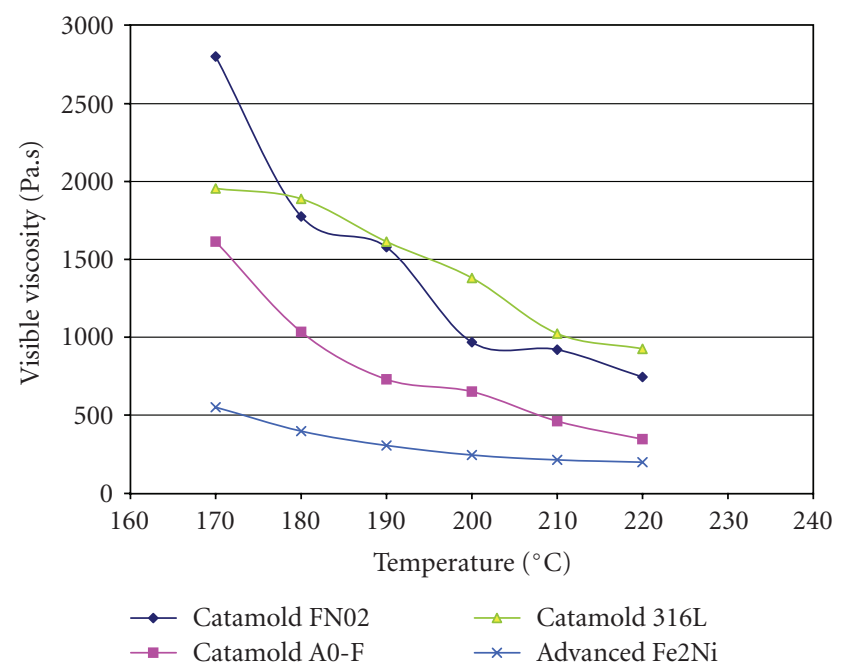

FIGURE 7: Temperature versus visible viscosity for present feedstocks (load 1,878 MPa).

The $V_{\min }$ and $V_{\max }$ values for normalization are given in Table 7.

\section{RESULTS AND DISCUSSION}

\subsection{Results of experimental analysis}

Variation of visible viscosities of Catamould FN02, A0-F, $316 \mathrm{~L}$ present feedstocks, and $\mathrm{Fe}-2 \mathrm{Ni}$ feedstock from advanced metalworking with temperature is given in Figure 7. While the viscosities of Catamould materials are in the same interval (2000-500 Pa.s), the viscosities of advanced metalworking $\mathrm{Fe}-2 \mathrm{Ni}$ are generally less than 500 Pa.s. The reason of this difference is originated from that the companies use different binder, size, and shape difference of powder and the different ratios of powder-binder. It is observed that there is a reverse ratio between flow rate, which is flow rate of feedstocks in viscosity graph (Figure 8 ) and visible viscosity.

It can be seen from the graphs in Figures 7 and 8 that Catamould materials have high viscosity and low flow rate and $\mathrm{Fe}-2 \mathrm{Ni}$ feedstocks have low viscosity and high flow rate.

Temperature versus yield length graph in zigzag mould for pressed feedstocks is represented in Figure 9. Here injection pressure and flow were kept to be 1000 bar and $15 \mathrm{~cm}^{3} / \mathrm{s}$, respectively. The variation of yield length with pressure (Figure 10) was examined under the conditions of $200^{\circ} \mathrm{C}$ and $15 \mathrm{~cm}^{3} / \mathrm{s}$ flow rate. Figure 10 represents the graph for the injection flow versus yield length. Here, injection 


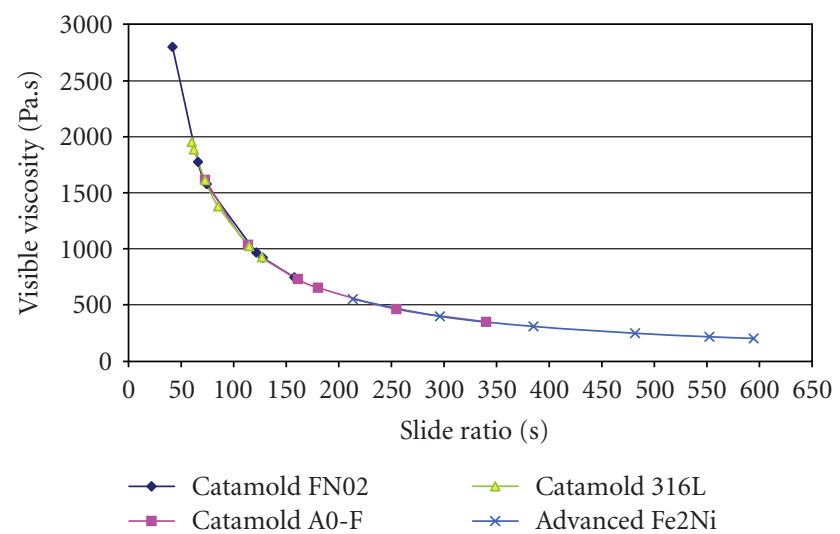

FIgURE 8: Slide ratio versus visible viscosity for present feedstocks (load $1878 \mathrm{MPa}$ ).

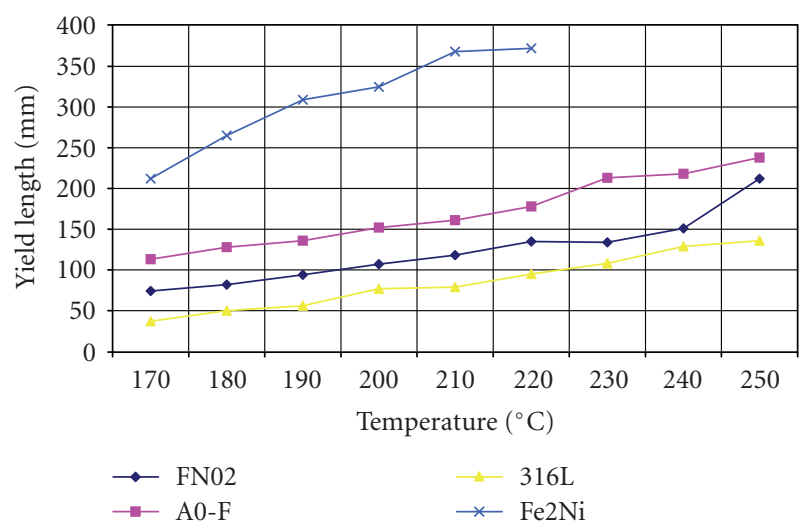

Figure 9: Yield length versus temperature graph for feedstocks.

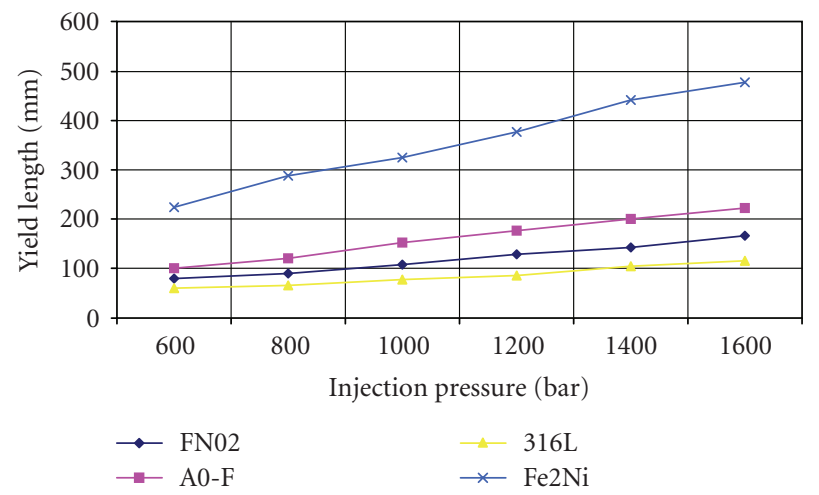

FIGURE 10: Yield length versus pressure graph for feedstocks.

pressure and temperature were kept as 1000 bar and $200^{\circ} \mathrm{C}$, respectively. In Figure 11, graph shows that there is flow increase in the interval of $10 \mathrm{~cm}^{3} / \mathrm{s}$ and $25 \mathrm{~cm}^{3} / \mathrm{s}$ for the Catamould materials. The graph in Figure 12 shows the variation of yield length versus pressure at $140^{\circ} \mathrm{C}$ mould temperature. Here cylinder temperature and flow were kept as $200^{\circ} \mathrm{C}$ and $15 \mathrm{~cm}^{3} / \mathrm{s}$, respectively.

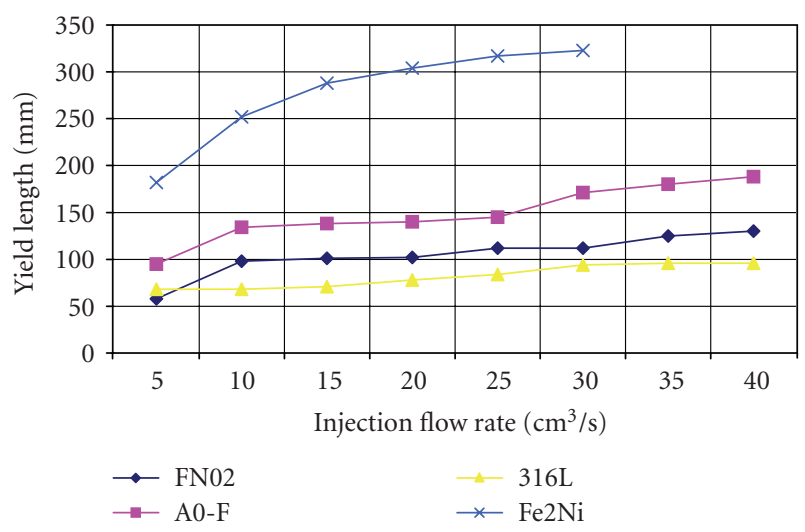

Figure 11: Yield length versus flow graph for feedstocks.

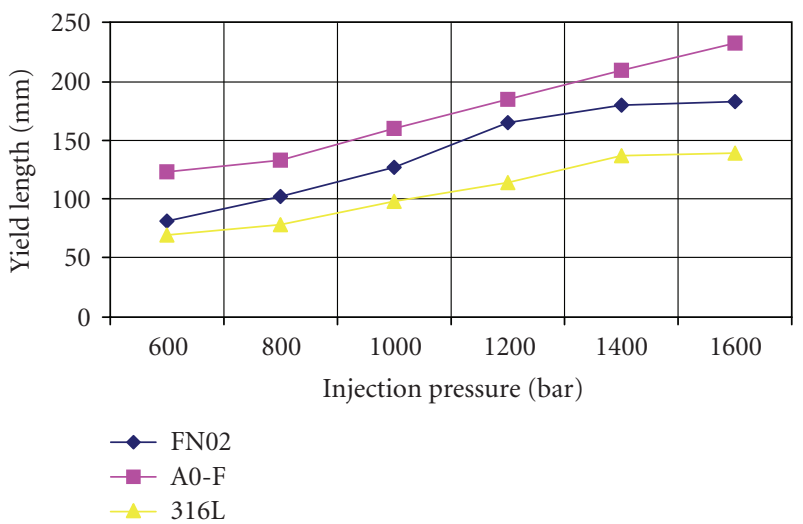

FIGURE 12: Yield length versus pressure graph for feedstocks produced for PIM by BASF at mould temperature of $140^{\circ} \mathrm{C}$.

It can be understood from the graphs that yield lengths of feedstocks in the mould increase gradually as follows: Catamould FN02, Catamould A0-F, Catamould 316L, and $\mathrm{Fe}-2 \mathrm{Ni}$ advanced metalworking. While the cylinder temperature versus yield length curves of feedstocks manufactured by BASF varies with the same manner (Figure 7), the graph of cylinder temperature versus yield length of the feedstock, $\mathrm{Fe}-2 \mathrm{Ni}$ by advanced metalworking, increases with a higher degree of slope. Since the viscosities and flow rates of Catamould and advanced metalworking materials are different, both temperature-yield length and pressure-yield length in zigzag canal of two feedstocks vary with different manner. This kind of behavior is caused by the different powder size and binder systems used by two companies. Catamould materials have shown lower separation at higher mould temperatures. This behavior is important to get an advantage for filling the small-sized vacancy. The longest yield lengths of materials were measured as $253 \mathrm{~mm}$ for advanced metalworking (at $220^{\circ} \mathrm{C}, 1600 \mathrm{bar}$, and $15 \mathrm{~cm}^{3} / \mathrm{s}$ ), $268 \mathrm{~mm}$ for Catamould $\mathrm{A} 0-\mathrm{F}$ (at $220^{\circ} \mathrm{C}, 1600 \mathrm{bar}$, and $15 \mathrm{~cm}^{3} / \mathrm{s}$ ), $211 \mathrm{~mm}$ for FN02 (at $230^{\circ} \mathrm{C}, 1600 \mathrm{bar}$, and $15 \mathrm{~cm}^{3} / \mathrm{s}$ ), and $150 \mathrm{~mm}$ for $316 \mathrm{~L}$ (at $230^{\circ} \mathrm{C}, 1600 \mathrm{bar}$, and $15 \mathrm{~cm}^{3} / \mathrm{s}$ ). The 


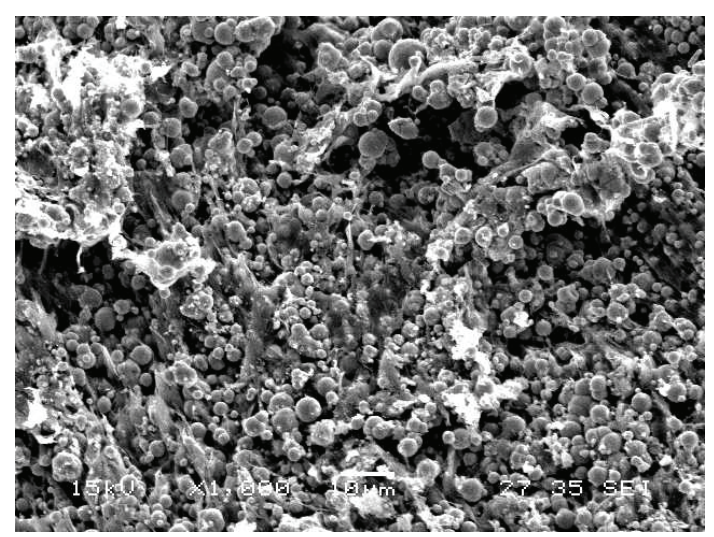

(a)

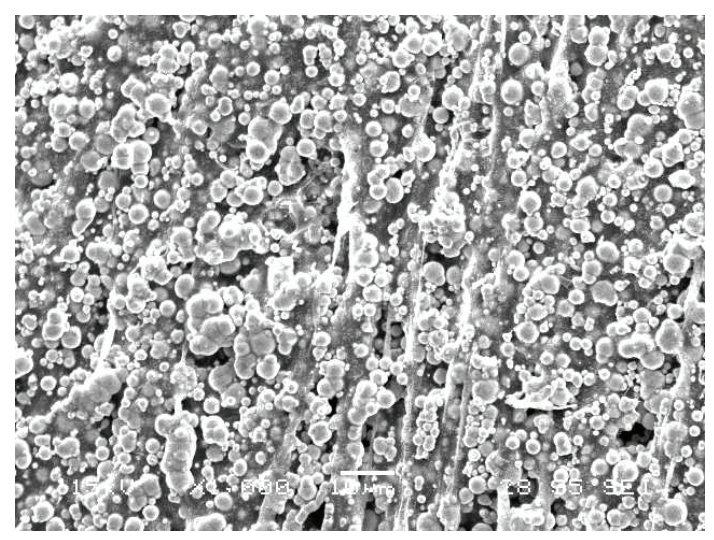

(c)

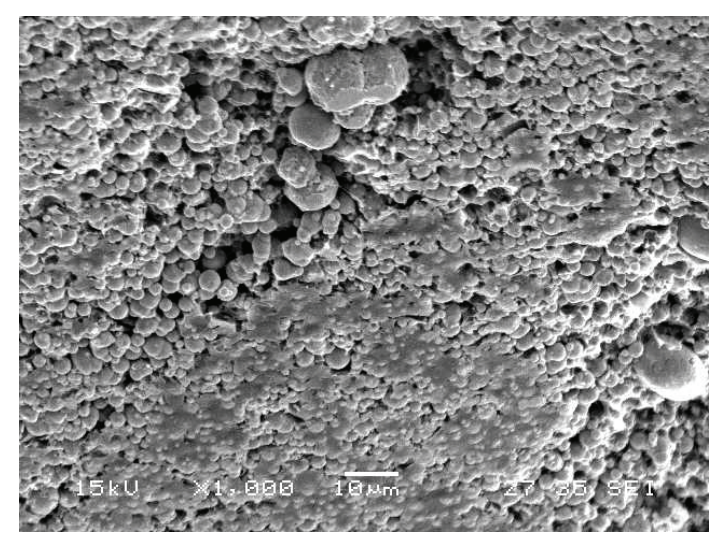

(b)

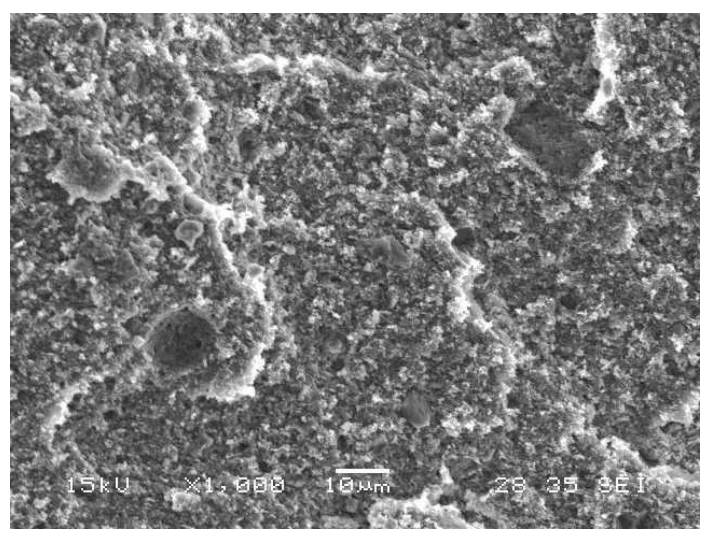

(d)

FIGURE 13: SEM micrographs of the end sections of samples with unresolved binder that are pressed into zigzag mould; (a) Fe-2Ni, (b) FN02, (c) 316L, (d) A0-F.

most appropriate injection parameters were found to be 180 $220^{\circ} \mathrm{C}$ cylinder temperature, $800-1200$ bar injection pressure, and $10-25 \mathrm{~cm}^{3} / \mathrm{s}$ flow intervals.

German [1], German and Bose [2], and Hens [13] have reported on literature that sudden directional changes lead to the aggregation of powders in aside and separation of powder and binder. This phenomenon is represented symbolically in Figure 3.

SEM micropictures taken from the end sections of samples, which are pressed at high speed of flow that leads the highest separation of powder/binder, pressed in zigzag moulds are given in Figure 13. Powder and binder structures are seen in clearly on the pictures. Figure 13(a), light areas show the binder rich zones and in dark areas powder remain separated. In Figures 13(b), 13(c), and 13(d) are taken from the samples pressed with Catamould FN02, Catamould 316L and Catamould A0-F, respectively. In Figure 13(c), powder grains are light because of brightness of stainless steel. A more homogeneous powder-binder structure can be seen Figures 13(b), 13(c), 13(d). From the view of In Figure 13 (d), it is difficult to distinguish the powder and binder due to the mixed-shaped ceramic powder involvement of the sam- ple pressed with Catamould A0-F. However, nonexistence of the dark area in the picture indicates that vacancy is not formed in the structure.

German and Bose [2] have reported that there is a moulding region in the combination of temperature and pressure to produce a high-quality part. They also argue that the graph of time versus other injection moulding parameters in Figure 1 can help to analyze the errors and problems.

In pressed prismatic samples, it is observed that burred sections are sticking on mould vacancy at high temperature and pressure while deficient filling at low temperature and pressure. Additionally, low ironing pressure and too high mould temperature lead to wreckage regions in the very thick sections of samples. Some pictures of samples pressed under different pressures are given in Figure 14.

\subsection{Results of theoretical analysis}

Figures 15-18 present the yield length (YL) simulated results versus YL experimental data for the testing database. Deviations between experimental results and theoretical results are very small for each parameter and negligible. Figures 15-18 


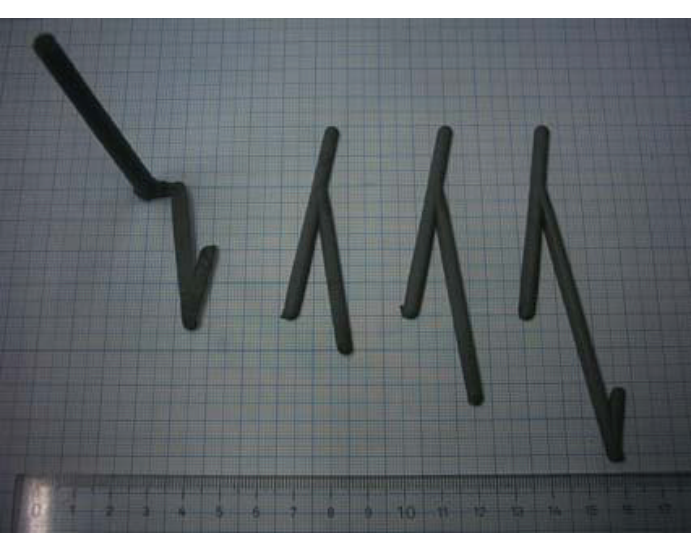

(a)

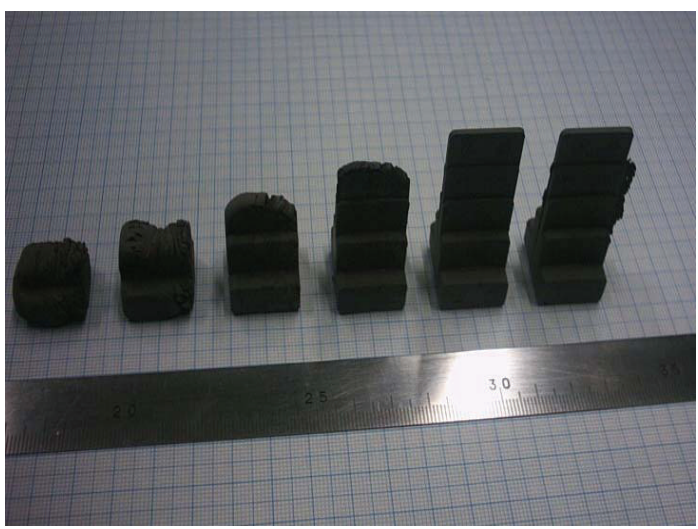

(b)

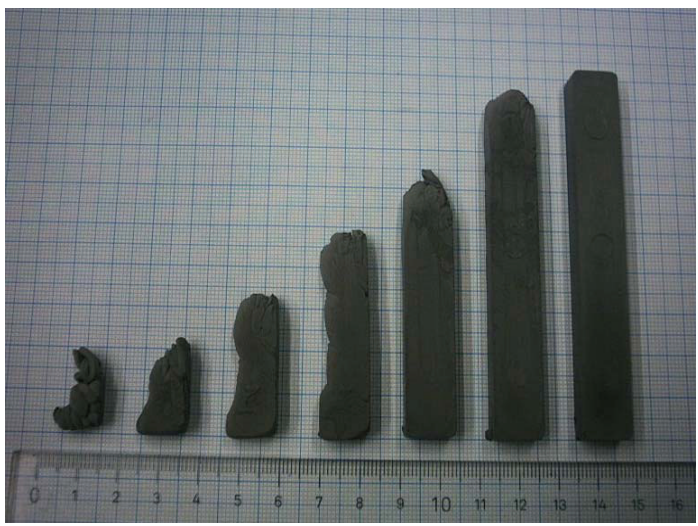

(c)

FIGURE 14: Pressed 316L stainless steel samples: (a) zigzag flow test, (b) five stepped part, (c) rectangular prism part.

show the model's ability to predict the YL values at different injection parameters for selected powder materials. As seen from results, ANN can be used for the determination of YL. From this correlation and statistical test, it is evident that the model was successful in predicting the experimental data of YL values. This shows the importance of the artificial neural network to determine the YL.

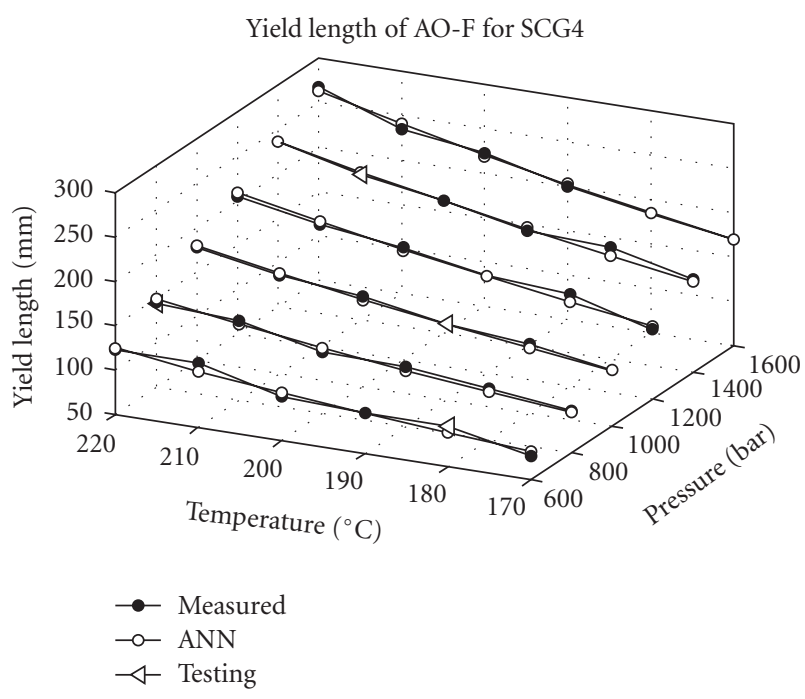

FIGURE 15: Comparison of the measured and predicted yield length based on temperature and pressure for A0-F.

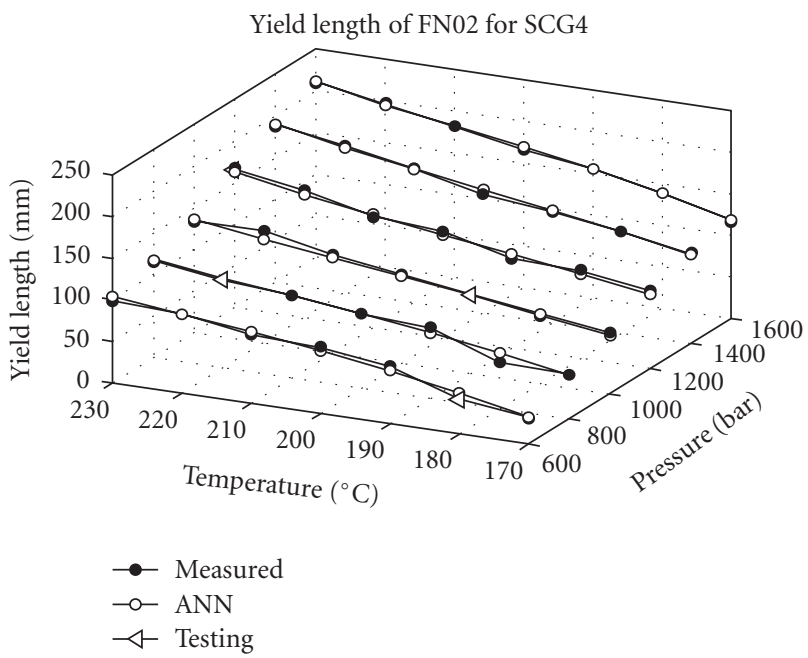

FIGURE 16: Comparison of the measured and predicted yield length based on temperature and pressure for FN02.

For YL, the best approach which has minimum errors is obtained SCG with 4 neurons for BASF firm Catamould A0F. Similarly, the best algorithm is SCG with 4 neurons, LM with 3 neurons, and LM with 4 neurons for FN02, Fe-2Ni, and $316 \mathrm{~L}$ stainless steel, respectively. For these approaches, Figure 19 and Table 8 show performance of ANN. The statistical error values for these approaches are given in Table 8 .

\section{CONCLUSIONS}

\subsection{Experimental analysis}

The following conclusions can be written for this study.

(i) Yield length of the feed stock proceeding in mould vacancy increases with increasing injection parameters such as pressure, temperature, and flow. 


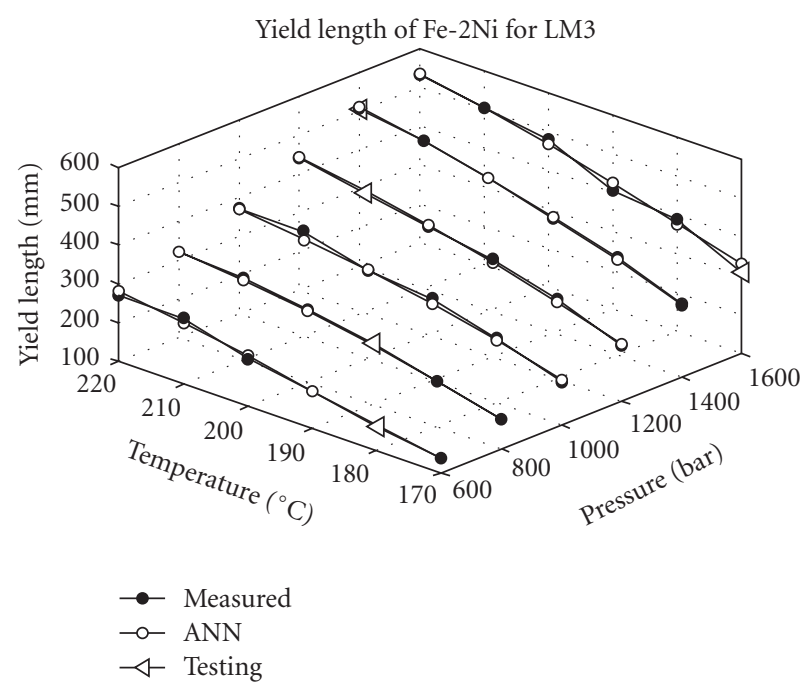

FIGURE 17: Comparison of the measured and predicted yield length based on temperature and pressure for $\mathrm{Fe}-2 \mathrm{Ni}$.

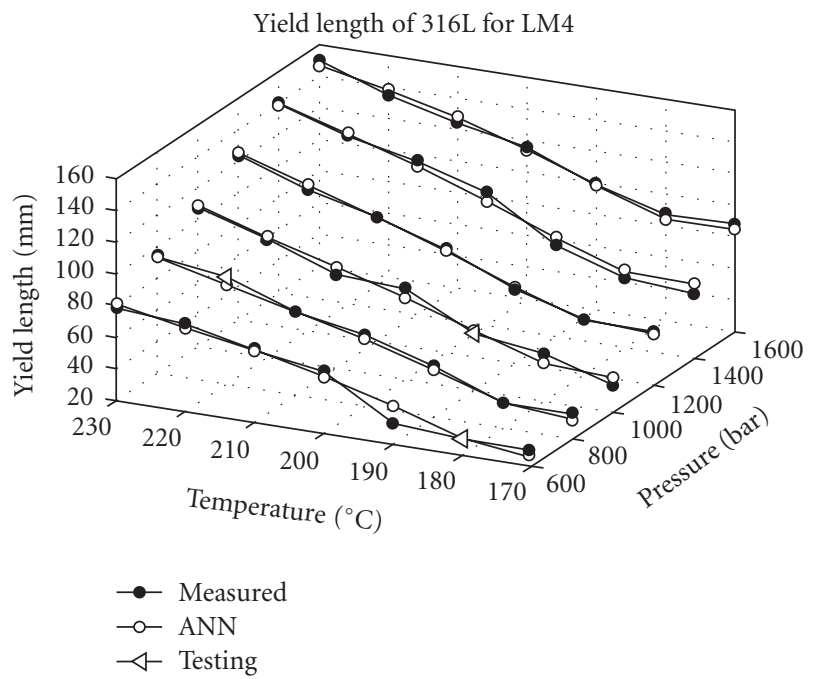

FIGURE 18: Comparison of the measured and predicted yield length based on temperature and pressure for 316L.

(ii) While the feedstocks have high viscosity, yield lengths are small, low viscosities lead to longer yield lengths.

(iii) The best flow conditions are feed pressures of 800 $1200 \mathrm{bar}$, mould temperatures of $180-220^{\circ} \mathrm{C}$, and flow of $10-25 \mathrm{~cm}^{3} / \mathrm{s}$.

(iv) Low pressure, temperature, and flow lead to deficient filling. Burred regions, wreckage regions, sticking to the mould, and separation of powder and binder occur under too high pressure, temperature, and flow conditions.

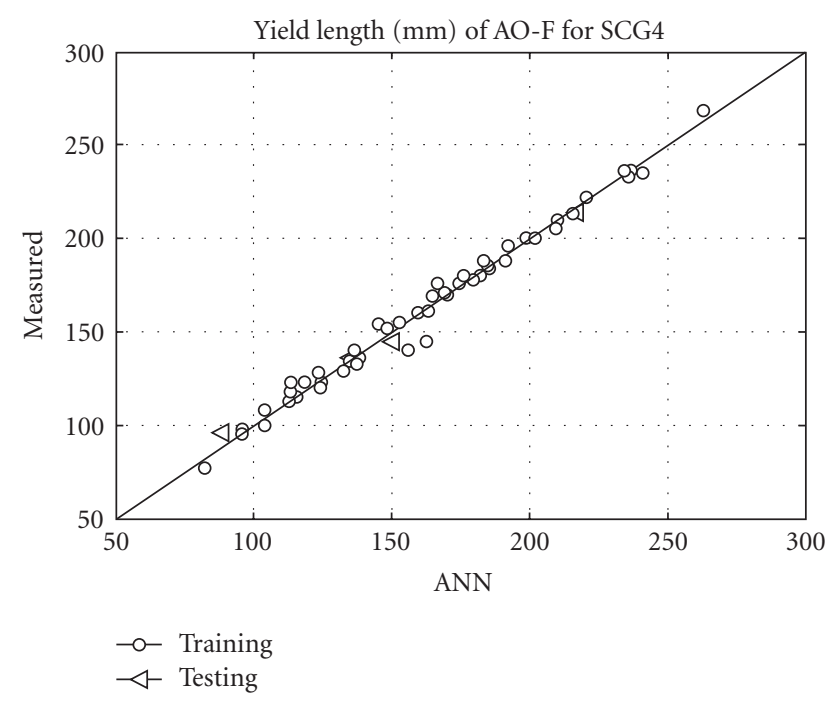

FIGURE 19: Comparison of the measured and predicted yield length for $\mathrm{A} 0-\mathrm{F}$.

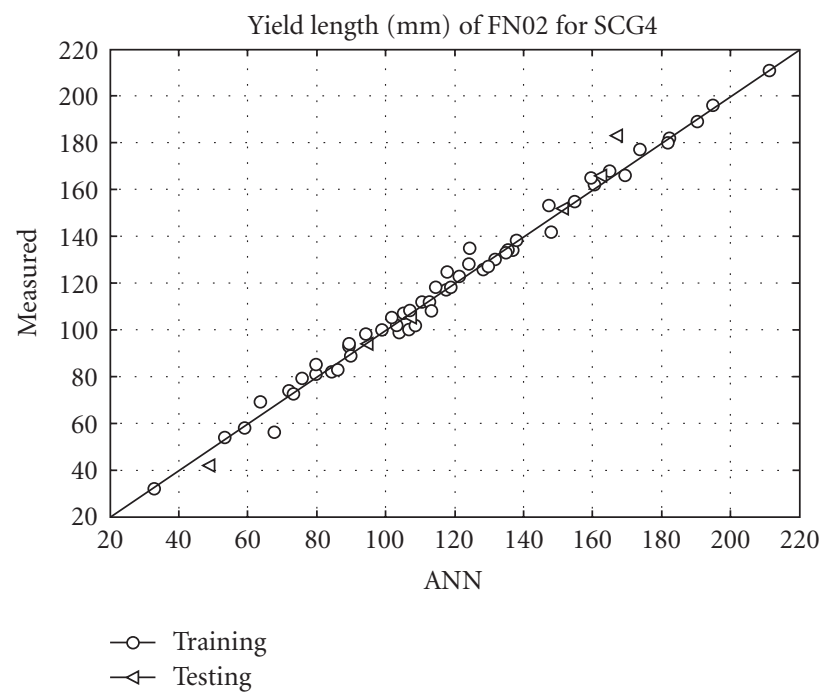

FIGURE 20: Comparison of the measured and predicted yield length for FN02.

\subsection{Theoretical analysis}

(i) The results of validation and comparative study indicate that the ANN-based estimation technique for yield length of the mouldability for feedstocks used in powder injection moulding is more suitable.

(ii) This study confirms the ability of the ANN to predict the yield length.

(iii) The results indicate that the ANN model seems promising for evaluating powder flow in the mould known injection parameters. 
TABLE 8: Statistical error values.

\begin{tabular}{l|c|ccc|ccc}
\hline \multirow{2}{*}{ Algorithm-neurons } & \multicolumn{2}{|c|}{ Materials } & \multicolumn{3}{|c|}{ Training data } & \multicolumn{2}{c}{ Testing data } \\
\cline { 2 - 7 } & & RMS & $R^{2}$ & MAPE & RMS & $R^{2}$ \\
\hline LM-3 & Fe-2Ni & 0.012531 & 0.999463 & 1.466718 & 0.01582 & 0.999129 & 2.50893 \\
\hline SCG-4 & BASF firm Catamould A0-F & 0.007364 & 0.999445 & 1.74265 & 0.005917 & 0.999666 & 1.841596 \\
\hline SCG-4 & FN02 & 0.005254 & 0.999574 & 1.71989 & 0.009779 & 0.998612 & 2.853247 \\
\hline LM-4 & 316L stainless steel & 0.004149 & 0.999593 & 1.708994 & 0.010765 & 0.997512 & 2.63659 \\
\hline
\end{tabular}

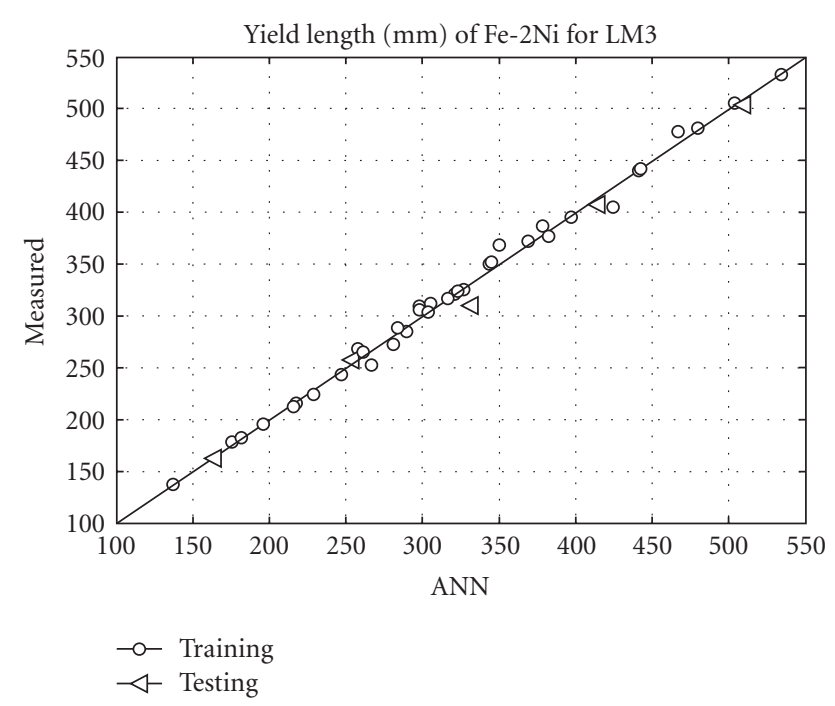

FIGURE 21: Comparison of the measured and predicted yield length for $\mathrm{Fe}-2 \mathrm{Ni}$.

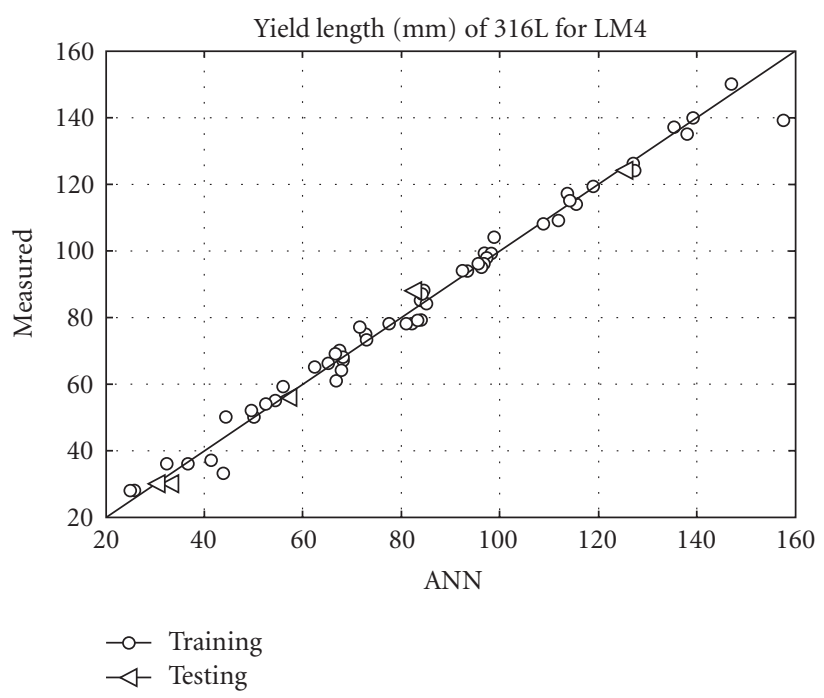

FIGURE 22: Comparison of the measured and predicted yield length for 316L.

\section{NOMENCLATURE}

\author{
YL Yield length $(\mathrm{mm})$ \\ P Pressure (bar) \\ CT Cylinder temperature $\left({ }^{\circ} \mathrm{C}\right)$ \\ FR Flow rate $\left(\mathrm{cm}^{3} / \mathrm{sn}\right)$ \\ MT Mould temperature $\left({ }^{\circ} \mathrm{C}\right)$ \\ p Pattern \\ $t \quad$ Target \\ o Output
}

\section{ACKNOWLEDGMENTS}

This research is supported by the Government Planning Organization of Turkey, under Award no. 2001K120590. The authors would like to thank Berfu Yoneyman from BAST and William R. Mossner from Advanced Metalworking Practices Inc. Also the authors thank Assistant Professor Dr. Hasan Okuyucu, Gazi University, for critically reviewing the original manuscript.

\section{REFERENCES}

[1] R. M. German, Powder Injection Moulding, Metal Powder Industries Federation, Princeton, NJ, USA, 1990.

[2] R. M. German and A. Bose, Injection Moulding of Metals and Ceramics, Metal Powder Industries Federation, Princeton, NJ, USA, 1997.

[3] M. Mohandes, S. Rehman, and T. O. Halawani, "Estimation of global solar radiation using artificial neural networks," Renewable Energy, vol. 14, no. 1-4, pp. 179-184, 1998.

[4] S. A. Kalogirou, "Applications of artificial neural-networks for energy systems," Applied Energy, vol. 67, no. 1-2, pp. 17-35, 2000.

[5] A. Palau, E. Velo, and L. Puigjaner, "Use of neural networks and expert systems to control a gas/solid sorption chilling machine," International Journal of Refrigeration, vol. 22, no. 1, pp. 59-66, 1999.

[6] K. S. Reddy and M. Ranjan, "Solar resource estimation using artificial neural networks and comparison with other correlation models," Energy Conversion and Management, vol. 44, no. 15, pp. 2519-2530, 2003. 
[7] A. Sözen, E. Arcaklioglu, M. Özalp, and E. G. Kanit, "Use of artificial neural networks for mapping of solar potential in Turkey," Applied Energy, vol. 77, no. 3, pp. 273-286, 2004.

[8] H. Bechtler, M. W. Browne, P. K. Bansal, and V. Kecman, "New approach to dynamic modelling of vapour-compression liquid chillers: artificial neural networks," Applied Thermal Engineering, vol. 21, no. 9, pp. 941-953, 2001.

[9] Ç. Karataş, A. Sözen, E. Arcaklioglu, and S. Erguney, "Modelling of yield length in the mould of commercial plastics using artificial neural networks," Materials \& Design, vol. 28, no. 1, pp. 278-286, 2007.

[10] A. Sözen, E. Arcaklioglu, and M. Özalp, "Formulation based on artificial neural network of thermodynamic properties of ozone friendly refrigerant/absorbent couples," Applied Thermal Engineering, vol. 25, no. 11-12, pp. 1808-1820, 2005.

[11] A. Sözen, M. Özalp, and E. Arcaklioglu, "Calculation for the thermodynamic properties of an alternative refrigerant (R508b) using artificial neural network," Applied Thermal Engineering, vol. 27, no. 2-3, pp. 551-559, 2007.

[12] K. F. Hens, D. Lee, S. T. Lin, and R. M. German, "Integrity of complex shape products by powder injection moulding," Powder Metallurgy International, vol. 23, no. 1, pp. 15-21, 1991.

[13] K. F. Hens, "Tooling and injection moulding powder injection moulding," in Proceedings of the International Powder Injection Moulding Symposium, State College, Pa, USA, July 1995.

[14] D. V. Rosato, Injection Moulding Handbook, Van Nostrand, Reinhold, NY, USA, 1984.

[15] N. Minagawa and J. L. White, "The influence of titanium dioxide on the rheological and extrusion properties of polymer melts," Journal of Applied Polymer Science, vol. 20, no. 2, pp. 501-523, 1976.

[16] Ç. Karataş, “Toz Enjeksiyon Kalıplamada Karışımın Reolojisi,” Doktora Tezi, Gazi Üniversitesi Fen Bilimleri Enstitüsü, Ankara, Turkey, 1997.

\section{AUTHOR CONTACT INFORMATION}

Çetin Karataş: Department of Mechanical Technology, Faculty of Technology, Gazi University, 06500 Ankara, Teknikokullar, Turkey; karatas@gazi.edu.tr

Adnan Sözen: Department of Mechanical Technology, Faculty of Technology, Gazi University, 06500 Ankara, Teknikokullar, Turkey; asozen@gazi.edu.tr

Erol Arcaklioglu: Department of Mechanical Engineering, Faculty of Engineering, Kırıkkale University, 71450 Kırıkkale, Ankara, Turkey; arcakli@yahoo.com

Sami Erguney: Department of Mechanical Technology, Faculty of Technology, Gazi University, 06500 Ankara, Teknikokullar, Turkey; erguney@yahoo.com 

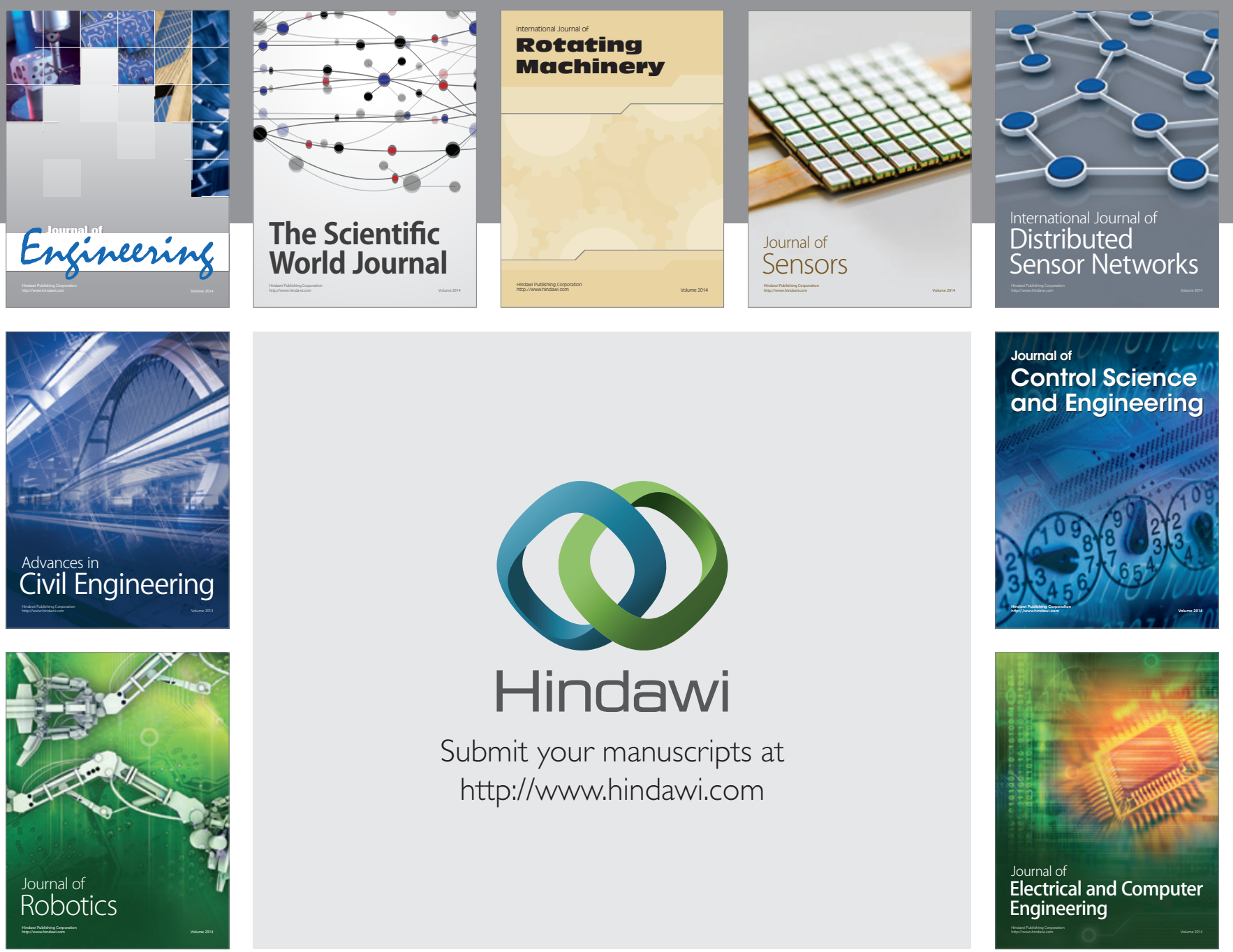

Submit your manuscripts at

http://www.hindawi.com
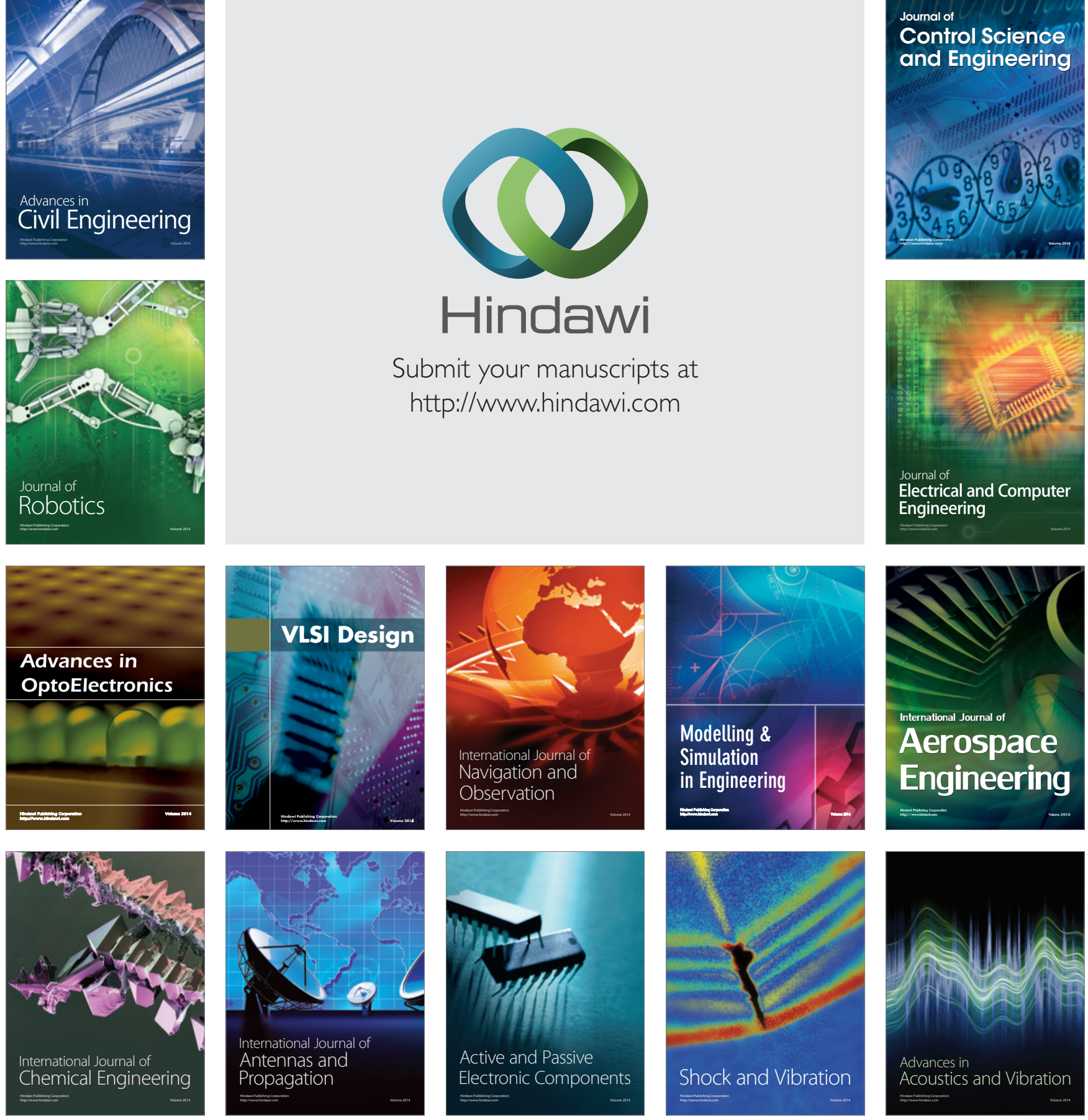